\title{
WASTE in THE LAND OF PLENTY: \\ AN EXAMINATION OF THE THEORETICAL IMPLICATIONS of WaSte on the Alberta OIL SANDS DEPOSITS
}

\author{
JASON METCALF*
}

Oilfeld waste is a concern addressed by legislation in both Alberta and Saskatchewan. This article examines the legal meaning of waste in contrast with practical examples of oilfield techniques that create unnecessary waste. The author notes that oil is not a renewable resource: thus, consenvation measures and the regulation of wasleful operations are appropriate measures from an economic perspective. While some waste is inevitable, statule and case law demand that cost-effective measures be saken to ovoid unnecessary waste. The policy mandate to prevent waste may be reduced to a simple point: the supply of oil is finite. and avoiding waste allows the maximum amount of profit from a limited resource.
Les déchets des infrastructures pétrolières préoccupen les législations de l'Alberia et de la Saskatchewan. Cet article examine la dimension juridique des déchets à l'opposé d'exemples pratiques de techniques pétrolières créant des déchets inutiles. $L$ 'auleur fait remarquer que comme le pétrole n'est pas une ressource renouvelable. des mesures de conservation et une réglementation sur / exploitation exageree sont des mesures qui s'imposent du point de vie economigue. Alors que cerfains dechets sont inévitables, les tois et la jurisprudence exigent que des mesures remlables soient prises pour éviter les déchets inutiles. Le mandat sur le plan des orientations qui consiste à prèvenir les dechets pourrait être réduit à un simple elèment, $c$ 'est-á-dire que les réserves de pitrole sont restreintes et qu ien limitan les déchets, on peut tirer un maximum de profits d'une ressources limilée.

\section{TABLE OF CONTENTS}

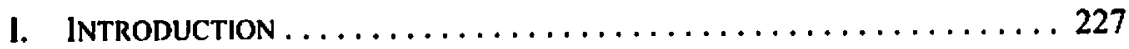

II. OF Oll SANDS AND BITUMEn RECOVERY $\ldots \ldots \ldots \ldots \ldots \ldots \ldots \ldots 228$

III. EXPLORING THE BOUNDARIES OF WASTE $\ldots \ldots \ldots \ldots \ldots \ldots \ldots \ldots 230$

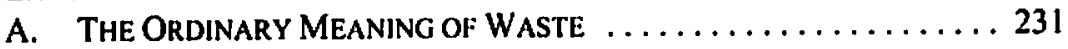

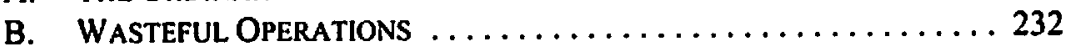

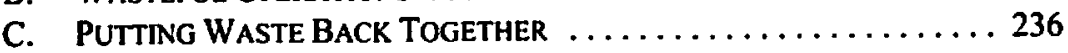

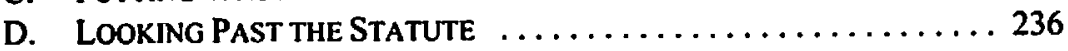

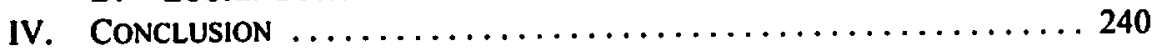

\section{INTRODUCTION}

"The waste of plenty is the resource of scarcity." Perhaps it was with these sage words in mind that the Provincial Legislatures of Alberta and Saskatchewan drafted conservation legislation to govern the exploitation of the bountiful oil and gas reserves of those provinces. ${ }^{2}$ This article explores the concept of waste as defined in Alberta's Oil Sands Conservation Act and provides a discussion of the policy implications behind the provisions dealing with

- B.S.C. (2004), LL.B. (2007), currently anticling with Macleod Dixon LLP. I would like to thank Professor Sharon Mascher for her encouragement and direction on this article, and the editors of the Alberta Law Review for their helpful comments in preparing for publication.

1 Thomas Love Peacock, Melincourt, or Sir Oran /lam-son (London: MacMillan, 1896) at 189.

2 The Oil and Gas Conservation Act, R.S.S. 1978, c. O-2; Oil Sands Conservation ACl, R.S.A. 2000, c. 0-7 [OSCA]; Oil and Gas Conservation Act, R.S.A. 2000, c. 0-6 as am. by Oil and Gas Conservation Amendment Act, R.S.A. 2000, c. 24 (Supp.) [OGCA]. 
waste. The article also endeavours to move that discussion out of the ethereal domain of theory by situating it within the context of actual projects in the oil sands of Alberta. It will be argued that in addition to what jurisprudence has revealed about waste, it is fundamentally a concept that is driven by economics, inherently fluid in its meaning, and flexible and selflimiting in its application. To give effect to this discussion, a brief overview of the various predominant technologies employed in the exploitation of oil reserves will first be outlined.

\section{Of OIL SANDS ANd Bitumen Recovery}

Gas and oil reserves can be roughly divided into two categories: conventional oil and gas pools, and unconventional heavy oil and oil sand deposits. ${ }^{3}$ Oil sand exploitation is achieved by one of two ways: strip mining, where the overburden depth is not very great, and in-situ recovery techniques where the depth of the oil bearing formation precludes mining (this technique applies to heavy oil shale deposits as well). ${ }^{4}$ Conventional oil deposits are recovered through the use and supplementation of pre-existing reservoir energy. ${ }^{5}$ These concepts will be further explored shortly.

In the practice of strip mining oil sands, the overburden is cleared and then bituminous ore is removed from the earth and hauled away for extraction. ${ }^{6}$ Strip mining is employed by both Suncor and Syncrude, the largest oil sands players in Alberta. ${ }^{7}$ The Clark hot water extraction process is the current standard in extraction in the oil sands, ${ }^{8}$ hot water is mixed with the ore to create a slurry which is then chemically treated and screened. The resultant mi a bitumen layer which is skimmed and a middling layer which is further processed to remove entrained bitumen. Tailings from the middling layer are disposed of after processing.'

Most oil sand plays require in-situ recovery of bitumen because of the depth of the reserves. ${ }^{10}$ Heavy oils and oil sands suffer from the same defects insofar as recovery is concerned in that neither resource has been exposed to sufficient temperature and pressure to cause extensive catalytic cracking of the hydrocarbon chains of which oil is comprised." The consequences which stem from this are twofold: first, there are relatively few gaseous hydrocarbons in the reservoir which can be relied on to provide pressure to aid recovery; and second, the average liquid hydrocarbon in the reservoir tends to be a long chain hydrocarbon which increases viscosity of the reserve. Indeed, were one to drill into such a reservoir intending to be completely reliant on the latent energy of the reservoir to provide the impetus

David L. Greene, Janet L. Hopson \& Jia Li, "Have we run out of oil yet? Oil peaking analysis from an optimist's perspective" (2006) 34 Energy Policy 515 at 516.

- S. Patel, "Canadian oil sands: Opportunities, technologies and challenges" (2007) 86 Hydrocarbon Processing 65 at 66.

$3 \quad$ Kenneth S. Deffeyes, Hubbert's Peak: The Impending IVorld Oil Shorlage (New Jersey: Princeton University Press, 2001) at 105-107.

6 M.M. Schumacher, ed. Ileayy Oil and Tar Sands Recovery and Upgrading (New Jersey: Noyes Data, 1982) at 283.

3 Alberta Energy und Utilitics Board (AEUB), Information Letter IL 84-06, "Mined Oil Sands Bitumen Processing Technology" (June 1983), online: AEUB <hutp:/www.eub.ca/ docs/ils/ils/pdf/il84-06.pdß at I [AEUB IL 84-6].

Ibid.

lbid.

Schumacher, supra note 6 at 281.

Ibid. at 12. 
for oil recovery, anywhere from 0 percent to a mere 8-10 percent of the oil in place would be recovered. ${ }^{12}$ This figure can be compared with conventional oil deposits that would yield anywhere from 20-60 percent recovery values of oil in place utilizing only the latent reservoir energy. ${ }^{13}$

Faced with the difficulties of recovery, creative engineers have employed a number of different techniques designed to overcome the innate hurdles of heavy oil/bitumen recovery in-situ. All the techniques rely on the same basic premise: if the viscosity of the heavy oil or bitumen can be reduced, recovery by traditional means becomes possible. ${ }^{\text {is }}$ Two common methods of reducing the viscosity of bitumen in-situ are Cyclic Steam Stimulation (CSS) and Steam Assisted Gravity Drainage (SAGD). ${ }^{15}$

CSS uses the same well bore for steam injection and recovery. ${ }^{16}$ The process is divided into three distinct phases: first, steam is injected into the reservoir for days or weeks; second, the well is capped off and the heat is allowed to penetrate the formation; and third, the oil is recovered. ${ }^{17}$ This process will continue for a number of cycles before production is diminished. If the reservoir has two or more wells drilled into it, CSS can then be converted to a steam drive, where one well (or wells) is used as an injection point and the other(s) can be used for recovery. ${ }^{18}$ Imperial Oil's Cold Lake project employs CSS. ${ }^{14}$

Similar to steam drive, SAGD operates in well pairs that are horizontally drilled along the bottom of the reservoir. ${ }^{20}$ One well constantly injects steam while the other well is used for recovery. ${ }^{21}$ Generation of steam for SAGD and CSS is typically accomplished through burning natural gas. ${ }^{22}$ SAGD projects are underway under the auspices of multiple different companies, and one such project that is in the initial phase of construction is the OPTI Canada Long Lake Project. ${ }^{23}$

Techniques for the recovery of conventional reserves are presented here for the purposes of comparison. Conventional oil and gas deposits have the natural advantage of high pressure to aid in recovery. Primary recovery of oil and gas occurs through the pressure provided by the gas cap that sits above the liquid hydrocarbons and by subsequent evolution of dissolved

Ibid. at 13.

Deffeyes, supra note 5 at 105 .

Schumacher, supra note 6 at 13.

Swapan K. Das \& Roger M. Butler. "Mechanism of the vapour extraction process for heavy oil and bitumen" (1998) 21 Joumal of Petroleum Science and Engineering 43.

Schumacher, supra note 6 at 293.

Ibid.

bid.

Disclosure Document for Cold Lake Expansion Project, online: Imperial Oil <www.limperialc.cal

Canada-English/Investors/Operating/Natural_Resources/ I_O_NaturalOilSandsDisclosure06.asp>.
Roger M. Butler, "Special Report: Future of EOR \& IOR - Application of SAGD, related processes growing in Canada" (2001) 99 Oil and Gas Joumal 74.

Nexen, "SAGD and Upgrader Integration." online: Nexen Inc.<http://www.nexeninc.com/Operations/ Athabasca_Oil_Sands/Long_Lake/SAGD.asp>.

Heritage Community Foundation. "Steam Assisted Gravity Drainage (SAGD)," online: Alberta's Natural Resources <http://www.abheritage.ca/abresources/inventory/resources_hydro_oilsands_dev_ silu_sagd.html>.

lbid. at 75 . 
gaseous hydrocarbons out of liquid hydrocarbons (or connate water). ${ }^{24}$ Secondary means that can be employed include water flooding of the reservoir and re-injection of produced gas back into the well; both techniques provide extra pressure to the reservoir. ${ }^{25}$ Tertiary recovery techniques or enhanced recovery techniques are the cutting-edge technologies employed to maximize production. These technologies tend to be quite expensive to deploy, but can dramatically increase recovery in the right circumstances. All the tertiary techniques operate by lowering the viscosity of the oil, thereby promoting the flow of the substances. ${ }^{26}$ These techniques include steam flooding, detergent flooding, fire flooding (in which air is injected into the reservoir and part of the oil is burnt, thereby providiung heat and pressure to drive the oil to a recovery well), and miscible flooding or Vapex (the injection of liquefied butane or propane or vaporized hydrocarbon solvents, respectively, into the reservoir to wash out the oil). ${ }^{27}$ Fire flooding and Vapex are potentially applicable in heavy oil and bituminous formations. Vapex is an experimental technology that may be commercially adopted at some point ${ }^{28}$ Fire flooding, used for many decades in conventional recovery, has been reinvented and used in the oil sands in the form of Toe-to-Heel-Air Injection (THAI) on a limited scale. $^{29}$

\section{EXPLORING THE BOUNDARIES OF WASTE}

The discussion of waste under the OSCA will look to the statutory provisions and definitions dealing with "waste." The ordinary meaning of waste will be explored as will the specifically enumerated heads of waste under the $A c t$. Ultimately, an underlying economic rationale of waste will be argued for through reference to the statute, jurisprudential policy analysis, and government policy as evidenced in Hansard.

Upon examination the $O S C A$, it is apparent that waste is taken very seriously under the Act. One of the few offences created by the Act is the commission of waste. ${ }^{30}$ Likewise, one of the stated purposes of the $A c r$ is to "effect conservation and prevent waste of the oil sands resources of Alberta." 31 This provision is meaningless of course without an understanding of what constitutes waste under the $\mathrm{ACt}$.

Under the $O S C A$, waste is defined in s. I(s) as: “'waste,' in addition to its ordinary meaning, means wasteful operations." ${ }^{32}$ Subsequently, "wasteful operations" are defined as follows in $\mathbf{s .} \mathbf{l}(\mathbf{t})$ of the Act:

$24 \quad$ Deffeyes, supra note 5 at 105.

2s $\quad$ lbid. at 106.

26 lbid. at 107.

27 Thid.

2* Das \& Butler, supra note 15.

20 U.S., Department of Energy, Heavy and Thermal Oil Recovery Production Mechanisms (Catifomia: Stan ford University, 2002) at 171. For insight into the experimental commercial uses of THAl in the oil sands, see "THAI TM Technology," online: Petrobank Energy and Resources Lid. <htip://www. petrobank.com/hea-thaitechnology.html>. 
(i) the establishment, construction, operation, suspension or abandonment of an oil sands site in a manner that results or tends to result in a reduction

(A) in the quantity or quality of oil sands, crude bitumen or derivatives of crude bitumen ultimately recovered from an oil sands deposil, or

(B) in the quantity or quality of oil sands products obtained from oil sands, crude bitumen or derivalives of crude bitumen

relative to that which would otherwise be recovered or obtained under sound engineering and cconomic principles,

(ii) the locating, drilling, equipping, completing, operating or producing of a well in a manner that causes or tends to cause excessive loss or destruction of crude bitumen, derivatives of crude bitumen or declared oil sands,

(iii) the inefficient storing on the surlace or underground of oil sands, crude bitumen, derivatives of crude bitumen or oil sands products, or

(iv) the production of oil sands, crude bitumen, derivatives of crude bitumen or oil sands products in excess of proper storage facilities or transportation and marketing lacilities or of market demand for them. $^{33}$

It is evident that waste is a composite term composed both of its ordinary meaning and the statutory meaning of wasteful operations. Although tempting, it would perhaps be a mistake to focus solely on wasteful operations to define what waste is under the Act. The Legislature has specifically indicated that the ordinary meaning of the word is to be given legal effect. ${ }^{34}$ As such, we will explore the implications of "waste" and "wasteful operations" to see if they are in fact distinct concepts.

\section{A. The Ordinary Meaning OF Waste}

The Paperback Oxford English Dictionary defines waste in three ways potentially relevant to this discussion: "I. Use carelessly, extravagantly, or to no purpose. 2. Fail to make full or good use of. 3. Destroy or ruin."

The first two definitions seem to impart the same meaning, namely, a failure to utilize some resource to its potential or for its stated purpose, through either inefficient management or prodigal use of the resource. The third definition imparts a sense of permanent injury to the resource; it will never be able to be used to its potential. The conjugation of the two concepts, it is submitted, forms the core of what "waste" should be under the Act. That is to say, waste is a failure to exploit bitumen reserves in a way which maximizes the potential 
capture of the reserves through, at minimum, the needless depletion of reservoir energy or destruction of the reserves.

\section{B. Wasteful Operations}

The portions of the $A c t$ referring to wasteful operations essentially provide that waste can occur at any part of an oil sand project, from the initial drilling, to the production, storage, and marketing of bitumen. Note that s. I(t)(iii) and s. I(t)(iv), reproduced above, act as absolute definitions of wasteful operations in that inefficiency in storage or overproduction of bitumen relative to storage, transportation capability, or market demand is unquestionably "waste." On the other hand, s. l(t)(ii) creates a relative type of waste. In (ii) it is clearly contemplated that destruction of bitumen, bitumen derivatives, or oil sand is not a wasteful operation unless it involves "excessive destruction." What constitutes "mere destruction" of bitumen and what is excessive destruction is a matter for debate. I submit that if the destruction of small quantitics of bitumen (relative to production volume) is the unavoidable consequence of operations in accordance with good oilfield practice, it will not constitute excessive destruction.

Assuming that collateral destruction of bitumen will not be regarded as wasteful operations, what should the result be where the operation fundamentally depends on the destruction of bitumen? The technology employed by Opti/Nexen at the Long Lake project could potentially attract castigation. ${ }^{36}$ Opti's patented OrCrude ${ }^{\mathrm{TM}}$ technology makes use of low commercial worth asphaltenes by catalytically cracking the recovered hydrocarbons into a synthetic gas. ${ }^{37}$ The synthetic gas is then used as fuel to generate the steam required for a conventional SAGD operation. ${ }^{38}$ The company estimates that out of a daily production of $70,000 \mathrm{bbl}$ of oil equivalents, $13,500 \mathrm{bbl}$ will be consumed by their gasification operation. ${ }^{39}$ This process involves far more than mere ancillary destruction of bitumen; the entire operation basically depends on the catalysis of almost 20 percent of the daily production in order to continue production, but is it "excessive destruction" so as to offend the $A c r$ ?

For policy reasons, this technology should not be regarded as causing excessive destruction of bitumen. Note that in all SAGD operations the use of steam is inherent. As mentioned earlier, steam is typically generated by heat from combustion of natural gas. ${ }^{40}$ So long as SAGD is used for in-situ recovery operations, fuel of some sort will be required to generate the steam. Opti's technology cleverly takes care of a major limiting expense in SAGD applications by providing a relatively cheap source of fuel with a static cost; with gas prices around \$5-8/Mcf, fuel costs alone for SAGD projects have been estimated to be \$5-

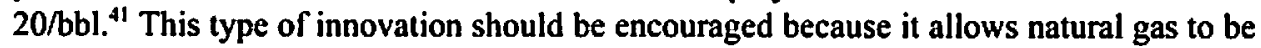
put to better uses within the market, makes valuable use of low commercial value hydrocarbons, and minimizes costs (which will in turn maximize profits and royalty shares).

\footnotetext{
"Technology," online: Long Lake Project <http://www.longlake.ca/project/lechnology.asp >. Opti Canada, 2004 Ammul Report, online: Opti Canada <http://www.opticanada.com/common/ uplosds/documents/pdis/2004\%20Annual\%20Report.pdis.

Ibid.

Jbid. at $\mathbf{S .}$

Butler, supra note 20 and accompanying text.

lbid. at 75.
} 
This method of recovery truly attempts to make good and full use of the bitumen reserves by paradoxically destroying a portion of the reserve. In finding that this practice would not be waste, the key is to recognize that the energy to recover these reserves must come from somewhere.

Section $1(t)(i)$, the first head of "wasteful operations" in the $O S C A$, also creates a relative type of waste. Two heads of waste are enumerated under subsection (i) and these portions of the statute, reproduced above, bear some kind of explanation. The two provisions are quite similar, but distinct in two specific ways: (A) makes reference to ultimate recovery from oil sand deposits while (B) refers to products derived from oil sands, crude bitumen, or derivatives from crude bitumen. ${ }^{42}$ The reference in (A) to "ultimate recovery from a deposit" implies that it is concerned with how an oilfield site is operated. The reference to "products" in (B) likewise implies that it is concerned with the subsequent manipulation of recovered oil. Therefore it would seem likely that $(A)$ is referring to operations of recovery, be it in-situ recovery or mining, whereas (B) is applicable to subsequent processing of ore, crude bitumen, or products derived from crude bitumen. The relative aspect of (i) is evident when we see that operation of an oil sands site which results in a reduction under $(A)$ or $(B)$ is only wasteful if it is a reduction relative to what would be recovered under "sound engineering and economic principles."

This issue necessitates a discussion of the meaning of "sound engineering and economic principles." First the concept of "sound engineering principles" will be examined, then a look at "economic principles" or "sound economic principles" will follow.

Under Alberta legislation, no one can engage in the practice of engincering unless that person is a professional engineer or a person so licenced to practice engineering. ${ }^{\text {H }}$ It would seem trite to say that if the practice of engineering is regulated such that only professionals or licenced individuals may engage in it, it must be carried out in accordance with "sound engineering principles." That is to say, sound engineering principles are those principles forming the basis for the practice of engineering as widely accepted by engineers.

As a result of this qualification, wasteful operations occur if recovery of bitumen could be enhanced through other techniques known to engineers. An argument can be put forth that such an assessment must be made with a specific oil sands project in mind. Choices for recovery techniques are commonly limited by site-specific factors such as: the overburden depth, pay thickness and extent, porosity and permeability of the bitumen-bearing formation, the percentage of oil saturation and oil in place, bitumen gravity, viscosity and chemistry, site location and climate, as well as water and electric power availability. ${ }^{\text {ts }}$ These factors need to be taken into consideration when assessing whether an operation is a wasteful one.

:2 OSCA, supra note 2. Sec portion of statute reproduced above.

4) Ihid., s. I(t)(i).

4 Sec Engineering, Goological and Geophysical Professions Act, R.S.A. 2000, c. E-11, s. 2(1) [Engineering Act]: "Exeept as otherwise permitted in this Act, no individual, corporation, partnership or other entity, except a professional engineer, a licensee so authorized in its permit or a certificate holder so authorized in the certificate holder's certificate, shall engage in the practice of engineering." 
Case law has dealt with this argument in at least one setting. In Husky Oil Operations Lid. v. Public Utilities Board ${ }^{46}$ a gas refinery was supplied with gas from two different producers. The two gas streams were processed concurrently and at different times. The refinery was more efficient when both fields were supplying the refinery. A dispute arose regarding the method of apportioning costs for the processing between the producers. The gas supplied by Husky Oil had a higher proportion of acid gas than gas supplied by Coseka, but Coseka supplied commensurately more gas. ${ }^{47}$ Before the Board, Husky argued that they should not pay more for processing because "on the basis of sound engineering principles, proven in numerous actual gas plant operations, the fuel gas requirements of a plant are directly proportional to the amount of acid gas produced. ${ }^{-18}$ The Board disagreed with the argument submitted by the appellant on the grounds that the expert opinions were based on theoretical calculations which did not take into account the operating data of the actual refinery. ${ }^{49}$ The Court of Appeal affirmed the Board's reasoning in this regard. ${ }^{50}$

Based on the physical differences in geological strata, hydrocarbon chemistry, physical environment, and the reasoning in Husky, it seems reasonable to conclude that recovery processes employed in other oil sands projects will be relevant to determining what constitutes wasteful operations in a particular project only insofar as the processes employed elsewhere would produce superior recovery results in the particular project.

Regarding the "economic principles," referred to in s. 1(t)(i) of the $O S C A,{ }^{51}$ there is a question of whether or not the phrase should be read to implicitly mean "sound economic principles" or merely "economic principles." I submit that the word "sound" adds nothing to the concept of to "economic principles" given the dictionary definition of "principle" as "a truth or general law that is used as a basis for a theory or system of belief." If "economic principle" is a truth which forms the basis for economic theory, then by definition it must be sound. Having decided that, what is an "economic principle"?

At the risk of providing an overly simplistic treatment of this area, it seems quite safe to say that an operation must be capable of producing a profit over the long term to be in accordance with economic principles. Profitability would appear to be the basic measurement by which economic decisions are made. Whether profitability is an economic principle or not is unknown, but it has been argued that the legal theorist Richard Posner holds that "maximization of wealth" is the "purpose of all human activity." $\$ 33$ Certainly such thought is of enormous pedigree, echoing from bygone centuries the sentiments of the English theorist John Locke, that in the state of nature a person was entitled to no more than required to satisfy need, but upon the creation of currency, one was entitled to all that labour could

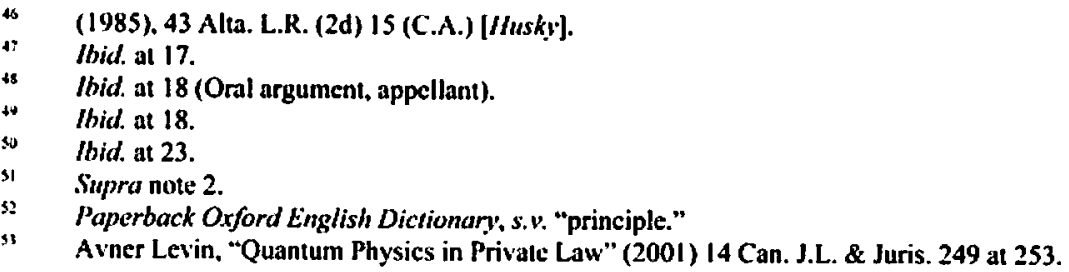


provide. ${ }^{54}$ If not the touchstone of economics, the pursuit of profit is so intrinsically linked to the core of economic thought and principle that it might as well be the same.

Arguably, if other types of recovery operations are capable of producing a greater degree of recovery from a reservoir (as per the engineering considerations of $O S C A, \mathrm{~s} .1(\mathrm{t})(\mathrm{i})(\mathrm{A})$ ), such operations will nevertheless fail to be a wasteful operation if the adoption of a more efficient recovery technique would be prohibitively expensive, unprofitable, or marginally profitable. Two rationales explain this concession by the $A c t$. First, the bottom line of a company in the exploitation of reserves must be respected in order to encourage exploitation of oil sand reserves. Second, if exploitation is deferred until the ideal technology is developed or the price of oil is high enough to warrant the use of very effective but very costly recovery techniques, successive governments will be deprived of substantial revenues and overall sector health will be diminished. For these reasons, a company may legitimately avoid the use of more efficient techniques of bitumen recovery or extraction without committing a wasteful operation. Without offering this protection to a company, the development of oil sands projects would be completely stunted.

Imperial Oil's Cold Lake project employs CSS instead of SAGD. It is possible that given the use of horizontal drilling technology in SAGD, and the use a feeder well in addition to a recovery well, the CSS technology may be inferior technology from an engineering perspective of recovery. If, after taking into account the relevant physical data which demonstrate the desirability of the use of SAGD, the question of economics could well save the CSS operation from incurring the label "wasteful operations." An assessment of waste at the economic stage would properly include an analysis of the remaining recoverable reservoir reserves and the benefit which would accrue by switching recovery means, balanced against the cost of the switch and its long-term profitability.

A quick comparison of the wasteful operations disallowed under the $O G C A$ shows that while there are differences between the $O S G A$ and the $O G C A$, the differences are largely explained by reference to the differing nature of the reserves. ${ }^{5 s}$ The primary substantive differences include references to reservoir energy, flaring, and failure to use enhanced recovery techniques; the balance of the clauses in $\mathrm{s}$. 1 (l)(ddd) of the $O G C A$, effectively cover the same ground as $\mathrm{s}$. $1(\mathrm{t})$ of the OSCA. Flaring and reservoir energy are dealt with specifically because of the high incidence of gas in conventional reserves and the absolute importance of that gas from a commodity standpoint and from a recovery point of view. Enhanced recovery techniques are al ways required in heavy oil and oil sands deposits, which is why the $O S C A$ does not mention them in the "wasteful operations" provision. Note that the concerns addressed in wasteful flaring and reservoir energy depletion are subsumed under s. 1(t)(i)(A) of the OSCA; their absence from the OSCA does not mean that the scope of waste is different under the two statutes. Practically speaking, both provide for similar conceptions of wasteful operations.

ss OGCA, supra note 2, s. I(1)(ddd): OSCA, supra note 2 at s. $1(t)$. 


\section{Putting Waste Back Together}

A difficulty arises when the broader term of waste is examined. Recall that under s. 1(s) "waste," in addition to its ordinary meaning, means "wasteful operations." ${ }^{\text {" How }}$ does the ordinary meaning of the term "waste" fit with "wasteful operations"? The language used indicates that wasteful operations is in caddition to the ordinary meaning. The ordinary meaning of waste is much broader than the definition of wasteful operations for the simple fact that the ordinary meaning allows for no exceptions to be made in deciding what constitutes waste. Thus, operations which are not "wasteful operations" would still not seem to escape the label of "waste" due to the ordinary meaning application.

However, if this interpretation were to result, it would be entirely nonsensical: clearly the legislation was intended to carve out exemptions from waste by use of the more specific term "wasteful operations." The use of the words "in addition" is really quite unfortunate, since they potentially render the specific provision nugatory. A sensible interpretation, which admittedly strains the statutory language, but makes sense in the result, is that "waste" is not to include operations which are not "wasteful operations." Such an interpretation, however, does make one wonder when the ordinary meaning of the word would or could ever bear on a determination of waste. One possible example will be cited later. Certainly "wasteful operations" seems broad enough on its own merits to largely promote the interests of the legislature.

\section{Looking Past the Statute}

Turning now to a policy discussion on waste which extends beyond the four corners of the statute, it will be argued that waste has an intrinsic economic rationale which provides a key to understanding the concept. As mentioned above, part of the rationale behind the definition of wasteful operations is to encourage the exploitation of oil sands by sanctioning the commission of operations which would otherwise constitute waste. As well, the jurisprudence highlights a new facet of waste in that what constitutes waste may be a moving target.

The jurisprudence has been largely quiet on informing our understanding of waste under the OSCA. Waste has been occasionally talked about in decisions, but usually in a manner tangential to the issue before the court. The relevant decisions insofar as they relate to waste will be quickly summarized and then discussed.

An important shut-in gas well case of Giant Grosmont Petroleums Ltd. v. Gulf Canada Resources $L t d{ }^{57}$ dealt with waste in a general fashion. This case dealt with a large number of gas wells that were shut-in in an oil sands region by the Alberta Energy and Utilities Board (AEUB) on the premise that the extraction of gas may constitute an unacceptable risk to the ultimate recovery of bitumen. The Board shut-in the wells using jurisdiction granted 
by regulations under the $O S C A$. These regulations were challenged and upheld by the Alberta Court of Appeal in Grosmont. ${ }^{58}$

The Court in Grosmont lays out some important history of gas production in the area that is important to our understanding of waste. Prior to 1983, it was economically unfeasible to extract buried bitumen, and there did not appear to be any technology on the horizon to make it feasible. ${ }^{59}$ As a consequence, rights for gas production were given almost invariably to producers. The SAGD operator in the area became concerned that the production of gas would cause a significant problem with ultimate recovery of bitumen, and the Board undertook a study to determine if that was the case. ${ }^{60}$ The Board found that gas production could likely affect bitumen recovery, but bitumen production would negligibly affect gas recovery. Moreover, the Board said that production of gas should not be allowed on the premise that superior recovery technology would be developed which would mitigate the harm caused by gas production. ${ }^{61}$ The Court of Appeal supported the jurisdiction of the Board (and the regulations which allowed them to shut-in the wells) by reference to the Board's mandate to conserve energy resources in the province. ${ }^{62}$

In Anderson v. Amoco Canada Oil and Gas, ${ }^{63}$ the Alberta Court of Queen's Bench was concerned about a split title issue, but the trial judge discussed the rationale behind the $O G C A$. Justice Fruman found that the $A c t$ 's rationale was to mitigate the rule of capture, specifically to prevent the undue and wasteful extraction methods which the rule of capture encouraged. ${ }^{64}$

Anderson highlights two of the major rationales of oil conservation legislation: the need for orderly economic development of reserves, and the curtailment of waste in production. Both of these ends promote efficiency of exploitation aimed at the maximization of the ultimate benefits of the resource. There is an undeniable economic element in this aim. Grosmont makes the economic case more clearly by reiterating the rationale behind privileging bitumen production over gas production. Simply put, the Board would not countenance the possibility that superior technology would be developed. Consequently, in determining which resource was to be preferred, future development is viewed with a frozen technological perspective which is aimed at the maximization of resource exploitation. Wasteful operations are avoided by preferring a plan of development that allows for the greatest possible amount of recovery given the tools of recovery at our disposal today. Such a plan of development is not concemed with maximization of bitumen recovery for the sake of bitumen recovery, but is completely driven by the maximization of realized economic gain.

On multiple occasions, the Minister of Energy in Alberta has made this same observation. Dr. Stephen West, the predecessor to the current Minister of Energy, remarked on the 
importance of the oil sands projects in providing employment and a high standard of living. ${ }^{6 s}$ Clearly, the less waste which occurs in the development of the oil sands, the greater the long term employment benefits of development will be, as well as the amount of tax dollars which will be generated over time. Murray Smith, the current Minister of Energy in Alberta, remarked that resource revenue in 2002 and 2003 was responsible for almost 30 percent of the Alberta government's revenue stream. ${ }^{66}$

Obviously, the provincial government is quite concerned with ensuring that development occurs in a way that maximizes their take from resources, but there is also an interest in ensuring that the kinetic energy employed in recovery techniques is maximized. According to Smith, this means that as conventional reserves begin to decline and new technology is employed in the oil sands, maximum use of energy must be made. In the context of steam generation for SAGD processes, this means that: "It's absolutely in the public interest ... for us to use that precious natural resource, natural gas, for more than just to generate steam from the oil sands." ${ }^{\circ 7}$ The Minister had previously indicated that cogeneration of electricity in SAGD processes makes a great deal of sense; why not pass the steam through a turbine to generate electricity before pumping it into a reservoir? While a failure to do this would be difficult to characterize as a wasteful operation, since bitumen recovery is unaffected by the generation of electricity or lack thereof, this situation could be a case for an appropriate application of the ordinary meaning of waste. If cogeneration could be employed in steam generation and it is not, then it is a failure to make full use of the resource which is "waste" under the "ordinary meaning" referred to in the $O S C A{ }^{68}$

Using the ordinary meaning of waste under the statute to mandate the use of cogeneration suggests another attribute of waste. Waste is a moving target whose meaning changes according to available technology. This must logically be the case (as will be explained), and indeed, this approach is reflected in government policy. Practically, the notion that the meaning of waste is linked to technological developments places a legal onus on operators to ensure that as other technology becomes available, their operations do not become wasteful.

Grosmont establishes that the AEUB has always employed a frozen perspective with regard to technology in allowing exploitation of reserves. ${ }^{64} \mathrm{However}$, this frozen perspective is employed in light of today's technology. This must necessarily be so for two reasons. First, one cannot assume that experimental methods of extraction or recovery will ever become cost efficient or capable of operating on the commercial scale. Consequently, only proven technologies can provide a standard for non-wasteful operations. Second, antiquated technology that was the gold standard for recovery or extraction in days gone by is no longer sufficient for a determination of what constitutes wasteful operations. Companies therefore run a very real risk of having operations which were once on the cusp of innovation languish into wasteful operations.

Alberta, Legislative Assembly, Subcommilte D, "Energy" in Alberla Hansurd, No. 1-25 (23 February 1998) at DI-D3 (Dr. Stephen West).

Alberta, Legislative Assembly, Alberia Honsard, No. 39-57 (6 May 2003) at 1454 (Murray Smith).

Ibid. at 1461 .

Supra note 2, s. 1(s).

Supra note 57. 
In the Information Letter issued by the AEUB, it was made clear that the Clark hot water process averaged less than 90 percent of bitumen by mass. ${ }^{70}$ The letter lists seven other technologies that could function as an alternative to the Clark hot water process. The Board is aiming at a widespread adoption of a technology which allows for 95 percent recovery of bitumen by mass. ${ }^{71}$ Particularly, they cite the Taciuk process as the best potential alternative to Clark hot water process. ${ }^{72}$ The Board has made it clear that as the technology becomes utilized on a commercial scale, a shift to the new technology will eventually become mandatory.

Interestingly, the Board writes the letter from the perspective of its obligation to ensure the orderly, efficient development of natural resources, which is ostensibly based on s. 3(b) of the $O S G A .^{73}$ There may be significant overlap between the statutory objectives of "efficient development" and prevention of "waste." Notwithstanding such overlap, a mandatory shift in the technology accords with the theory of waste more strongly than the aims of efficient development because of the Board's emphasis of improving ultimate extraction yields, a factor which is related directly to "waste" under the umbrella of "wasteful operations." Until such a shift in technology becomes practicable from an engineering and economic perspective, the current extraction process cannot incur the label of wasteful operations. The qualifying proviso "relative to that which would otherwise be recovered or obtained under sound engineering and economic principles"74 will continue to shelter the process from the disapprobation of the $A c t$.

In summing up the discussion of waste, one more topic must be addressed. This area is so troublesome that most will downplay its implications by deferring its consequences to a future, far, far away. This cold, unattractive subject is the bare fact that oil reserves are finite.

The vast extent of the bitumen resources in Alberta has almost become proverbial. In contemplation of such vast resources, it is enticing to entertain the illusion that the reserves will last forever. Nevertheless, world consumption of oil is enormous, and demand is increasing on a yearly basis. ${ }^{75}$ In 1956 , Dr. M. King Hubbert pointed out that it would take an infinite amount of oil to satisfy a fixed percentage increase in demand for oil. ${ }^{76}$ In Hubbert's Peak, Deffeyes cogently makes the case that Hubbert's original prediction of peak oil production in the United States applies to the world production of oil, and that very soon the spectre of diminishing yearly production of oil will become a reality if it is not a reality already. ${ }^{77}$ Does this, or should this fact inform our understanding of waste?

AEUB IL 84-6, supra note 7 at 1.

lbid.

Ibid. at 3.

Ibid.at I; OSGA, stupra note 2.

OSGA, ibid, s. 1(t)(i).

Deffeyes, supra note 5 at 133-50.

Ibid. at 150.

Ibid. at 158. 


\section{CONCLUSION}

It is submitted that the finite nature of oil is the absolute underpinning truth upon which a theory of conservation is based. If exhaustion of a resource is an impossibility, then conservation measures are meaningless. Take for example the light of the sun, which but for the operation of the third law of thermodynamics, is a resource that cannot be utterly consumed. Leaving aside concerns about the environment, regulations prohibiting the harvesting of energy from the steady fall of photons upon the earth would be simply absurd. Clearly, the same cannot be said for oil, which despite its apparent cornucopia-like abundance, has a limit more firmly established than the waves of the oceans.

The limit of oil "written in the reservoir rocks, in the source rocks, and in the cap rocks" is the ultimate reason why the $O G S A$ is concerned with waste. Insofar as waste goes, the concerns of the $A c t$ are reduced to a fiscal equation. This equation isn't too hard to follow, just multiply the price per barrel by the number of barrels in the ground, and the overarching reason for the $A c t$ 's mandate "to effect conservation and prevent waste" simplicity. In achieving the maximum amount of profit from the limited resources of the oil sands, there is some tension between exploiting the maximum amount of oil theoretically possible, and exploiting the maximum amount of oil possible given technological and economic constraints. Waste in its ordinary sense would favour the first approach, forbidding exploitation unless the maximum amount could be achieved. The Act has, however, allowed for a more nuanced theory of waste by preferring the second approach, suggesting that exploitation must be allowed on a continual basis, with the goal of maximum exploitation ever before us. Because of the adoption of such a refined standard of waste, it is theoretically broad enough to advance more than the objective of prevention of waste. Though ill-used by the courts, this concept could well form the basis of an ongoing duty owed to no less than the government of Alberta as the owner of the resources, and by extension the people of that province. 